\title{
A NEW ENRICHMENT MEDIUM FOR CERTAIN SALMONELLAE
}

\author{
BY \\ F. RAPPAPORT, N. KONFORTI, AND BETTY NAVON \\ From the Municipal Hadassa Hospital, Tel-Aviv, Israel
}

(RECEIVED FOR PUbLiCaTION JULy 18, 1955)

A great number of enrichment media for Salmonellae have been described in the medical literature. Some of them have gained wide acceptance in many clinical laboratories. Two of the most frequently used enrichment media are tetrathionate broth in various modifications (Muller, 1923 ; Kauffmann, 1930 ; Preuss, 1949 ; Knox, Gell, and Pollock, 1942) and selenite broth (Hobbs and Allison, 1945).

The purpose of an enrichment medium for Salmonellae is twofold: it has to enable the pathogens to multiply freely and it should inhibit or kill all accompanying coliform organisms. Particularly troublesome are Proteus, Pseudomonas pyocyanea and Aerobacter aerogenes, which are not always inhibited in the enrichment media mentioned. These organisms grow after subculturing on solid indicator media such as Salmonella shigella medium (SS) and a great number of lactose-negative colonies must be examined in order to detect Salmonella.

A medium which satisfies both criteria of enrichment has been developed in this laboratory. The use of this medium was responsible for the detection of almost twice as many cases of salmonellosis as when the two other standard enrichment media were used.

\section{Materials}

Enrichment Media.-Tetrathionate broth was prepared as follows:

$\begin{array}{lccccc}\text { Nutrient broth } & \ldots & \ldots & \ldots & 90 \mathrm{ml} \text {. } \\ \mathrm{CaCO}_{3} & \ldots & \ldots & \ldots & \ldots & 5.0 \mathrm{gr} \text {. } \\ \text { Sodium thiosulphate } & \ldots & \ldots & 5.0 \mathrm{gr} \\ \text { Ox bile } & \ldots & \ldots & \ldots & \ldots & 5.0 \mathrm{ml} .\end{array}$

Each ingredient was sterilized separately by autoclaving and when sterile all ingredients were aseptically added to nutrient broth, followed by $1 \mathrm{ml}$. of 1:1000 brilliant green and $2 \mathrm{ml}$. of lugol solution. A modification of this medium with malachite green instead of brilliant green was also used (Wild, 1952).

Sodium selenite broth was prepared according to the method of Hobbs and Allison (1945).

The new enrichment medium magnesium chloridemalachite green required the following:

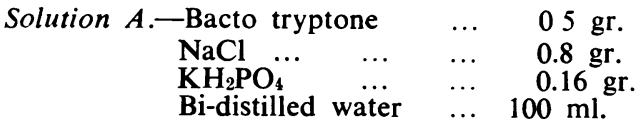

Solution B.-For this $40 \mathrm{gr}$. of $\mathrm{MgCl}_{2}$ (C.P.) is dissolved in $100 \mathrm{ml}$. water (it is advisable to dissolve the entire contents of $\mathrm{MgCl}_{2}$ from a newly opened container according to the formula, as this salt is hygroscopic).

Solution C.-A $0.4 \%$ solution of malachite green in distilled water is required.

For use, to each $100 \mathrm{ml}$. of solution $A$ is added $10 \mathrm{ml}$. of solution $B$ and $3 \mathrm{ml}$. of solution C. The final medium is distributed in $5 \mathrm{ml}$. quantities in test tubes, autoclaved for $20 \mathrm{~min}$., and stored in a refrigerator.

Differential media are SS agar medium (Difco), Kligler iron agar, and urea indol medium (Rappaport and Henig, 1951).

\section{Technique}

The stool to be examined was emulsified as a 1:1000 suspension in saline. Three to four drops of this suspension were dropped into $5 \mathrm{ml}$. of the following enrichment media: tetrathionate, sodium selenite enrichment broth, and the new enrichment medium. After an incubation of 16 to 18 hours a loopful of each of the enrichment media was plated on SS agar. Lactose-negative colonies on SS were inoculated into Kligler's iron agar and urea indol medium (Rappaport and Henig, 1951), and were examined serologically.

Evaluation of the results was based on two criteria : the ratio of positive findings from one enrichment medium to positive findings from another and the presence or absence of contaminants.

During the course of development of the new medium, when various ingredients at various concentrations were tried, essentially the same procedure as described above was followed. We used artificially infected stool suspension by adding to a Salmonellafree suspension of faeces a small number $(1-100)$ of Salmonella paratyphi $A$, Salmonella paratyphi $B$, and $S$. typhi, respectively.

\section{Development of the New Medium}

Inorganic Salts and Dyes.-The use of hypertonic magnesium chloride in the new medium follows the 
findings of Dold and Ketterer (1943), Lie Kian Joe (1950), and Lodenkämper (1952). They reported that, when various strains of intestinal bacteria were dried on sterile filter paper, their sensitivity to dehydration was different. Proteus and Escherichia coli were found to be more sensitive to drying than Shigellae and Salmonellae. It was, therefore, assumed and experimentally confirmed that this property could be used for differential isolation of Salmonellae from mixed cultures ; after drying, certain coliforms are eliminated while Salmonellae or Shigellae stay alive. We have assumed that similar results would be obtained by using a hypertonic solution of various salts, since in them bacteria would be dehydrated. This hypothesis was tested and resulted in development of an enrichment medium described elsewhere (Rappaport, Skariton-Loewenthal, and Olitzki, 1953).

Further experiments showed that hypertonicity was not the only factor operative in differential killing of bacteria. It was found that the ion used was of importance. The following salts were tried for their selective inhibitory powers: $\mathrm{MgS}_{2} \mathrm{O}_{3} . \mathrm{MgBr}_{2}, \mathrm{MgCl}_{2}$, $\mathrm{Mg}\left(\mathrm{NO}_{3}\right)_{2}, \mathrm{BaCl}_{2}, \mathrm{CaS}_{2} \mathrm{O}_{3}, \mathrm{Ca}\left(\mathrm{NO}_{3}\right)_{2}, \mathrm{CaBr}, \mathrm{CaI}_{2}$, $\mathrm{KNO}_{3}$, and $\mathrm{BeCl}_{2}$. Magnesium chloride was chosen as the most selective salt. Concentrations of $\mathrm{MgCl}_{2}$ above $8 \%$ in the basic medium, solution $A$. were inhibitory to all intestinal bacteria except Salmonella paratyphi. At a concentration of $4 \% E$. coli and Proteus were inhibited to a certain degree while Salmonellae were not affected at all (Table I). Below this concentration no effect of $\mathrm{MgCl}_{2}$ could be demonstrated. When the optimal concentration of $\mathrm{MgCl}_{2}$ was thus established, inhibitory dyes were added at varying concentrations and their effect observed: pyronin, ethyl malachite green, propyl malachite green (Edward Gurr), light green, setoglaucin. erioglaucin, eriogruen, brilliant green (J. R. Geigy, A.G.), gentian violet, methylene blue. methyl green,

\section{TABLE I}

INHIBITION OF GROWTH OF SALMONELLAE AND OTHER INTESTINAL BACTERIA BY $\mathrm{MgCl}_{2}$

\begin{tabular}{|c|c|c|c|c|c|}
\hline $\begin{array}{c}\text { Concentration }(\%) \\
\text { of } \mathrm{MgCl}_{2} \text { in } \\
\text { Solution } \mathrm{A}(\mathrm{MM})\end{array}$ & 4 & 6 & 8 & 12 & 16 \\
\hline $\begin{array}{l}\text { Growth of } S . \text { typhi } \\
, \quad, \quad \text { para- } \\
\text { typhi B", } \\
\text { Growth of * proteus, } \\
\text { E. coli, etc. }\end{array}$ & $\begin{array}{l}\ldots+ \\
\ldots+ \\
\ldots+\end{array}$ & $\begin{array}{l}++ \\
\ldots+\cdots \\
+\div\end{array}$ & $\begin{array}{c}\mp \\
-\ldots \\
-\end{array}$ & $\begin{array}{c}\cdots \\
-\end{array}$ & + \\
\hline
\end{tabular}

malachite green, crystal violet, basic fuchsin, acid fuchsin (Ciba), acid green, xylenecht (Sandoz), methanil yellow, chrysoidin, leuco-malachite green. Of all these dyes malachite green was found to be the most suitable, thus confirming again its selective value demonstrated first by Loeffler in 1903 and then again by Schönberg and Wiidik (1937). It should be stated at this point that the presence of malachite green in the medium at the concentration necessary to prevent contaminants from growing is definitely toxic to Salmonella typhi. No other dye was found which would be inhibitory to coliforms but not to S. typhi.

The optimal concentration of malachite green in the final medium was chosen according to experimental results shown in Table II. The mixture of malachite green with $\mathrm{MgCl}_{2}$ is more toxic than either component alone. While $4 \% \mathrm{MgCl}_{2}$ in the presence of $0.012 \%$ of malachite green did not affect any of the Salmonellae, marked inhibitory effects were observed at higher concentrations of either component.

Peptones.-The importance of the type of peptone used in selective or enrichment media has already been stressed by Biechteler (1952). He recognized the importance of using tryptic digest peptones in the Wilson-Blair medium. We tried the following peptones in the basic enrichment medium: N-Z-cazeine peptone (Sheffieid), tryptose, bacto-peptone, neopeptone, tryptone, proteose No. 3 (Difco), trypticase, myosate, thiotone $(\mathrm{BBL})$, casein proteolysate, peptone siccum (Merck). Of all these peptones tryptone (Difco) was found to be superior for growth of Salmonellae.

Experimental Evaluation of Enrichment Media.The degree of enrichment of Salmonellae and inhibition of coliforms was experimentally tested by inoculating the enrichment medium with a faecal suspension artificially contaminated with varying numbers of Salmonellae. This was done by using a procedure similar in certain respects to that employed by Lang (1952). A suspension of a recently isolated strain of $S$. paratyphi $B$ was made in saline, and was serially diluted in tenfold steps in saline. The same Salmonella suspension was similarly diluted in a $1: 1000$ Salmonellafree faecal suspension. From each dilution tube a loopful was plated on SS agar and at the same time 3 drops inoculated into the enrichment medium. After 16 to 18 hours a loopful from the incubated enrichment medium was plated on to SS agar. Control counts of Salmonellae plated on plain agar plates and

TABLE II

GROWTH OF S. PARATYPHI A AND S. PARATYPHI B IN NEW ENRICHMENT MEDIUM

\begin{tabular}{|c|c|c|c|c|c|c|c|c|c|c|c|c|c|c|c|c|}
\hline \multirow{3}{*}{$\begin{array}{c}\text { Concentration } \\
\text { of } \underset{(\%)}{\mathrm{MgCl}_{2}}\end{array}$} & \multicolumn{8}{|c|}{ S. paratyphi $A$} & \multicolumn{8}{|c|}{ S. paratyphi B } \\
\hline & \multicolumn{16}{|c|}{ Log Dilution from Enrichment Medium Showing Grcwth on SS Agar } \\
\hline & 1 & 2 & 3 & 4 & 5 & 6 & 7 & 8 & 1 & 2 & 3 & 4 & 5 & 6 & 7 & 8 \\
\hline $\begin{array}{r}4 \\
6 \\
8 \\
12\end{array}$ & + & $\begin{array}{c}- \\
\div \\
\because\end{array}$ & $\begin{array}{l}+ \\
+ \\
-\end{array}$ & + & $\begin{array}{l}- \\
- \\
-\end{array}$ & $\begin{array}{l}- \\
- \\
-\end{array}$ & + & $\begin{array}{l}- \\
- \\
-\end{array}$ & $\begin{array}{l}+ \\
+ \\
+\end{array}$ & 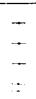 & $\overline{-}$ & $\dot{-}$ & $\overline{-}$ & $\begin{array}{l}- \\
- \\
-\end{array}$ & 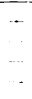 & - \\
\hline
\end{tabular}


on SS agar showed no significant differences. The faecal suspension used for dilutions contained $5 \times 10^{i}$ microorganisms $/ \mathrm{ml}$. The results of tests performed as above showed that the degree of multiplication in enrichment medium of Salmonella suspended in saline or in faecal suspension was of the same order, and a population of approximately $2 \times 10^{7} / \mathrm{ml}$. was reached from each Salmonella inoculated. It was also found that coliforms disappeared and a practically pure culture of Salmonella was obtained (Fig. 2b). If 1-5 organisms of Salmonella were mixed with $10^{6}$ coliforms in the new enrichment medium then the Salmonellae would be isolated.

Quantitative experiments were performed in order to demonstrate the growth of Salmonella and inhibition of $E$. coli from a mixture inoculated into the new enrichment medium. Samples of tenfold dilutions of a suspension of $\mathrm{S}$. paratyphi $B$ in saline were added to a suspension of $E$. coli, containing $3 \times 10^{7}$ organisms/ $\mathrm{ml}$. From these mixtures $0.1 \mathrm{ml}$. was inoculated into $5 \mathrm{ml}$. of the new medium. By this means 25,250 , and 2,500 Salmonellae were inoculated accompanied by $3 \times 10^{6} \mathrm{E}$. coli. From each tube of the new medium

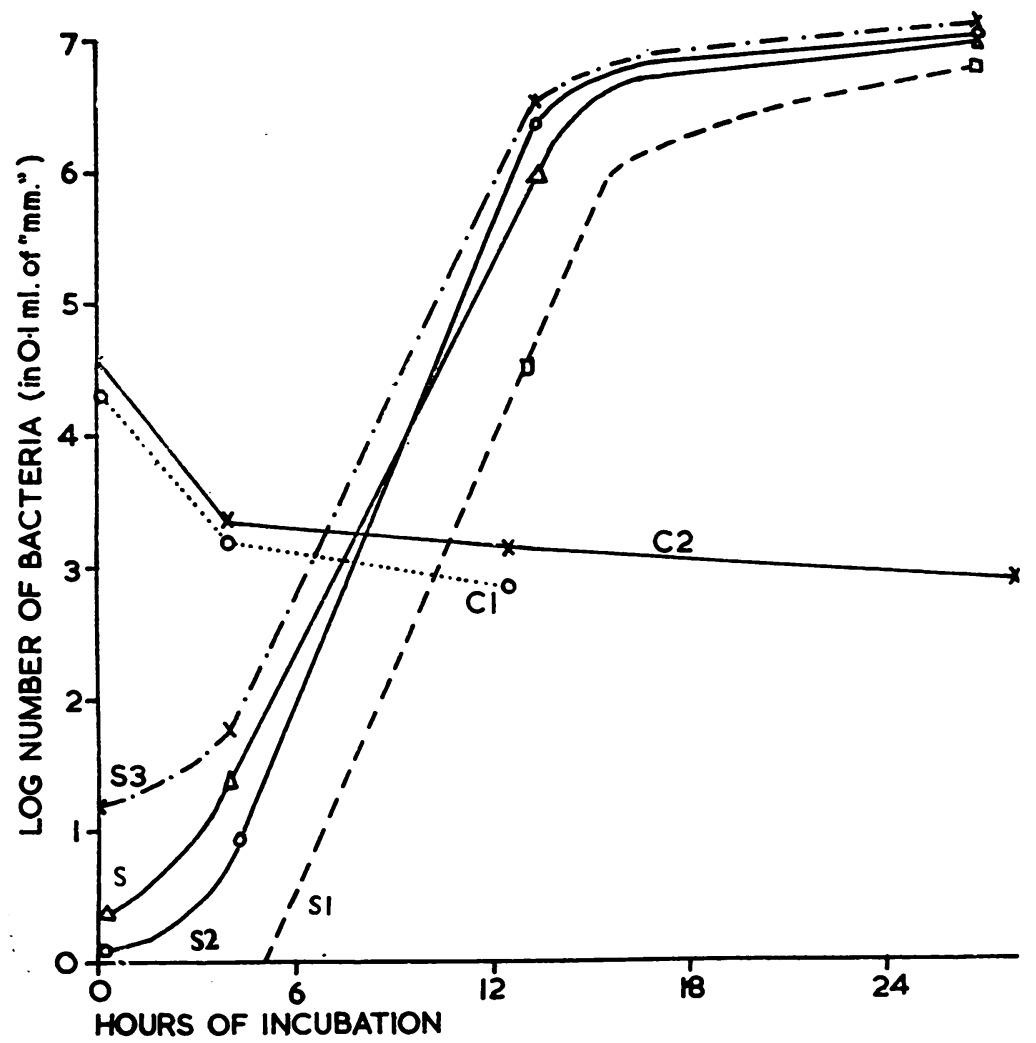

Fig. 1.-Growth of $S$. paratyphi $B$ and of $E$. coli from a mixture inoculated into the new enrichment medium (mm.). $\mathrm{Cl}=E$. coli in presence of Salmonella, $\mathrm{C2}=E$. coli control (without Salmonella). $\mathrm{S}=S$. paratyphi $B$ control (without $E$. coli). $\mathrm{S} 1, \mathrm{~S} 2$, and $\mathrm{S} 3=S$. paratyphi $B$ in presence of $E$. coli. Each tube of the new enrichment medium was inoculated with $2.5 \times 10^{8}$ of $E$. coli and $25(\mathrm{~S} 1), 250(\mathrm{~S} 2)$, and 2,500 (S3) organisms of S. paratyphi $B$. samples were taken after five, 13 , and 27 hours' incubation; the samples were diluted in tenfold steps and assayed on SS medium by plating $0.1 \mathrm{ml}$. of each dilution. As controls two tubes of the new medium were tested, one inoculated with $S$. paratyphi $B$ alone and the other with $E$. coli alone. The number of colonies of $E$. coli growing on SS agar was about half the number which grew on nutrient agar. $S$. paratyphi $B$ gave equal counts on SS and on nutrient agar. The results of one such experiment are graphically represented in Fig. 1. After five hours of incubation there is already an increase in the numbers of Salmonella, and colonies could be seen on SS agar in spite of an overwhelming growth of $E$. coli. After 13 hours of incubation in the new enrichment medium, the predominant growth on the plates was Salmonella. Even on plates inoculated with a sample of the new medium originally containing one Salmonella organism in $0.2 \mathrm{ml}$., after 13 hours' incubation there were 100 times more Salmonellae than $E$. coli. At the end of the logarithmic growth phase, after about 16 hours, Salmonella outnumbered $E$. coli by $30,000: 1$.

The only quantitative comparative results reported on enrichment media were made by Lang (1952, 1954), who mixed various proportions of Salmonellae with either $E$. coli or Proteus or A. aerogenes, inoculated them into several enrichment media and determined the maximum ratio at which Salmonella would yet grow. He found that the best enrichment and selective media were those of Bierbrauer (Lang, 1952) and Wild (Lang, 1954). Both media are modifications of the Mueller-Kauffman tetrathionate broth. Bierbrauer increased the selectivity of the medium by the addition of $0.01 \%$ malachite green and $0.0025 \%$ brilliant green. Wild's medium is solid and contains only $0.002 \%$ malachite green. In Bierbrauer's medi u m Salmonellae would grow even when inoculated with $E$. coli at a ratio of $1: 30,000$. This ratio is termed by Lang the "valency coefficient." In the original Mueller-Kauffman medium the valency coefficient is only $3: 11$. The efficiency of Bierbrauer's medium in relation to Proteus and A. aerogenes was found by Lang (1952) to be much lower than that in relation to $E$. coli. 
TABLE III

COMPARISON OF ENRICHMENT EFFICIENCY OF THREE MEDIA

\begin{tabular}{|c|c|c|c|c|c|c|c|c|c|c|c|c|}
\hline \multirow{2}{*}{ Medium } & \multicolumn{7}{|c|}{ Number of Pathogens Isolated in Group } & \multirow[b]{2}{*}{ Total } & \multirow[b]{2}{*}{$B$} & \multicolumn{3}{|c|}{$\mathrm{SI} \%$} \\
\hline & A & B & $\mathrm{C}$ & $\mathrm{D}$ & $\mathrm{E}$ & $\mathrm{G}$ & - & & & $\mathrm{C}$ & Others & Total \\
\hline $\begin{array}{c}\text { I } \\
\text { II }\end{array}$ & $\begin{array}{l}4 \\
5 \\
6\end{array}$ & $\begin{array}{l}16 \\
21 \\
39\end{array}$ & $\begin{array}{l}16 \\
31 \\
53\end{array}$ & $\begin{array}{l}- \\
3 \\
\end{array}$ & $\begin{array}{l}1 \\
3 \\
5\end{array}$ & $\overline{1}$ & 1 & $\begin{array}{r}37 \\
64 \\
111\end{array}$ & $\begin{array}{l}38 \cdot 1 \\
500 \\
92.9\end{array}$ & $\begin{array}{l}276 \\
534 \\
91.0\end{array}$ & $(*)$ & $\begin{array}{l}30 \cdot 8 \\
52 \cdot 1 \\
92 \cdot 5\end{array}$ \\
\hline $\mathbf{I}+\mathbf{I I I}$ & 5 & 24 & 34 & 3 & 3 & - & 1 & 70 & $57 \cdot 1$ & $58 \cdot 6$ & & $58 \cdot 3$ \\
\hline $\mathrm{I}+\mathrm{II}+\mathrm{III}$ & 7 & 42 & 58 & 6 & 5 & 1 & 1 & 120 & $100 \cdot 0$ & 1000 & & $100 \cdot 0$ \\
\hline$\underset{I I-I I I}{I+I I I}$ & $\begin{array}{l}7 \\
7\end{array}$ & $\begin{array}{l}41 \\
41\end{array}$ & $\begin{array}{l}56 \\
57\end{array}$ & $\begin{array}{l}6 \\
6\end{array}$ & $\begin{array}{l}5 \\
5\end{array}$ & 1 & 1 & $\begin{array}{l}117 \\
118\end{array}$ & $\begin{array}{l}97 \cdot 6 \\
97 \cdot 6\end{array}$ & $\begin{array}{l}966 \\
98 \cdot 3\end{array}$ & & $\begin{array}{l}97 \cdot 5 \\
98 \cdot 3\end{array}$ \\
\hline
\end{tabular}

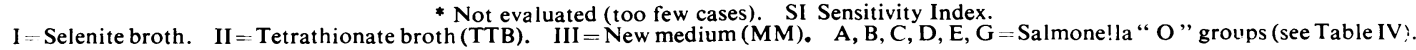

Using Lang's criteria, the new enrichment medium is superior to Bierbrauer's, and its valency coefficient is of the order of $1: 10^{5}-10^{6}$, compared with $1: 30,000$ in Bierbrauer's medium. This is true both in relation to $E$. coli $i$ and to a mixture of all coliforms in a faecai suspension.

Clinical Evaluation.-During the year 1954 stool samples of patients admitted to hospital were routinely tested by the described enrichment procedure in order to detect the presence of Salmonellae. All samples were enriched in the three media described. Of 3,391 stools examined, altogether 120 Salmonellae were isolated. Their distribution according to frequency of isolation from each enrichment medium is shown in Table III, and the identification of the strains is given in Table IV. According to Gillert (1954) the yield of the isolated pathogens by a given method should be compared to the yield obtained by the largest possible number of bacteriological methods. This was done, and the number of Salmonella strains isolated by all three methods employed was taken to be equal to $100 \%$. On this basis all other results were calculated. The ratio of the number of pathogens isolated by a given method to the total number isolated by all three methods was termed the "sensitivity index" (Table III). From the series presented in the table it may be seen that the new enrichment medium permitted the detection of $92 \%$ of all cases, while the selenite enrichment broth detected only $31 \%$ and the tetrathionate broth $52 \%$. When in addition to the new medium one other enrichment medium, either selenite or tetrathionate, was used, $98 \%$ of cases were detected.

The fact that selenite and tetrathionate broths are not suitable for enrichment of certain Salmonellae was pointed out by Banwart and Ayres (1953). They studied the growth of six species of Salmonella in various enrichment broths and on various selective media. S. paratyphi was found to be inhibited by tetrathionate broth and $S$. anatum by selenite. Lang (1954). describing the very promising results obtained on Wild's tetrathionate medium, remarks that this medium is inhibitory to $S$. pullorum and $S$. abortus equi.

Of great importance is the fact that the new enrichment medium effectively prevents the development of intestinal bacteria accompanying the Salmonellae. There were eight times more contaminated cultures on SS agar when plated from selenite broth and four times more when plated from tetrathionate broth, than when the inoculum was taken from the new medium. Its freedom from contaminants is strikingly demonstrated in Figs. $2 a$ and $2 b$.

Selenite broth was reported by Leifson (1936) to inhibit faecal cocci and enterococci within eight to 12 hours, while $S$. typhi multiplied from the start. Similar results were described by Macierewicz. Strzelecka, and Zaleska (1954). However, Proteus and $P$ s. pyocyanea were not inhibited in this medium. The presence of contaminants such as E. coli, Ps. pyocyanea, $A$. aerogenes, and yeasts in inocula from tetrathionate and selenite broth has been also observed by Biechteler (1952).

Another factor contributing to freedom from contamination, which we find of importance in our en-

\section{TABLE IV}

TYPES OF SALMONELLAE ISOLATED BY ENRICHMENT PROCEDURE

\begin{tabular}{|c|c|c|c|c|c|}
\hline \multicolumn{2}{|r|}{ Pathogens Isolated } & \multicolumn{4}{|c|}{ Media } \\
\hline Group & Species & Number & $\underset{\text { Three }}{\text { In All }}$ & $\begin{array}{l}\text { In } \\
\text { Two }\end{array}$ & $\begin{array}{c}\text { In } \\
\text { One* }\end{array}$ \\
\hline A & S. paratyphi A . . & 7 & 3 & 2 & 2 \\
\hline B & $\begin{array}{l}\text { S. paratyphi } B \\
\text { S. typhi murium }\end{array}$ & 42 & 12 & 10 & 20 \\
\hline $\mathrm{C}$ & $\begin{array}{l}\text { S. paratyphi } C \\
\text { S. braenderup } \\
\text { S. newport } \\
\text { S. montevideo } \\
\text { S. muenchen } \\
\text { S. emek } \\
\text { S. nachshonim }\end{array}$ & 58 & 11 & 20 & 27 \\
\hline D & S. enteridis & 6 & - & 3 & 3 \\
\hline$E$ & $\begin{array}{l}\text { S. meleagridis } \\
\text { S. london } \\
\text { S. taksony }\end{array}$ & 5 & 1 & 2 & 2 \\
\hline$G$ & S. poona .. & 1 & - & - & 1 \\
\hline \multirow[t]{2}{*}{-} & S.tel-aviv & 1 & - & 1 & 1 \\
\hline & Total pathogens. & 120 & 27 & 38 & 55 \\
\hline
\end{tabular}

* On new enrichment medium. 


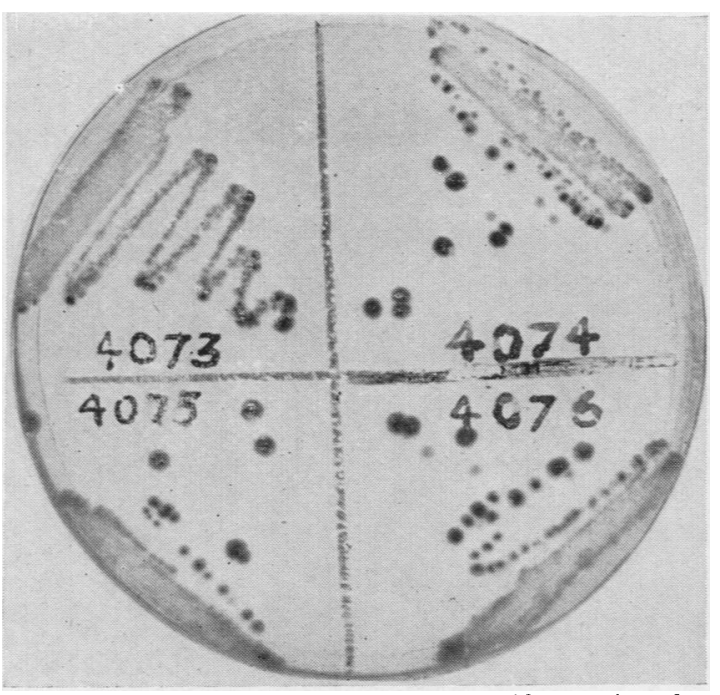

FIG. 2a.-Smear from tetrathionate broth on an SS agar plate after 18 hours of incubation. The enrichment broth was inoculated with 3 drops of faecal suspension $(1: 1,000)$.

richment procedure, is the use of relatively dilute faecal suspensions. In tetrathionate and selenite broths this dilution allows the growth of coliforms. In spite of this dilution growth of Salmonellae in the new medium was practically unrestricted, one organism being sufficient to start growth in presence of $10^{6}$ coliforms. Fig. 3 demonstrates the importance of dilution of faeces before inoculation into enrichment media. Only in inocula containing less than $1: 1,000$ dilution of faeces, lactose-positive colonies were found. A simple calculation shows that in the case presented in Fig. 3 even 0.1 micrograms of faeces was sufficient to initiate growth of $S$. enteritidis in the new medium.

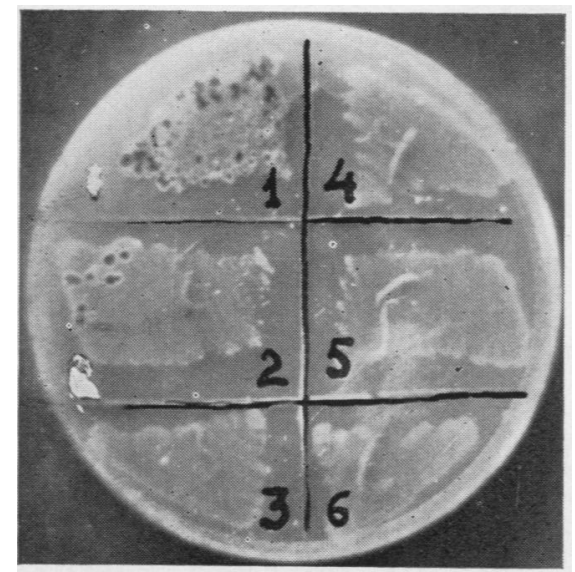

FIG. 3.-An SS agar plate inoculated from the new enrichment medium. Numbers denote logarithm of dilution of faeces inoculated into the medium. From dilutions $10^{-3}$ to $10^{-6}(3-6)$ grew only $S$. enteritidis. I actose-positive colonies were present in dilutions 1 and 2 .

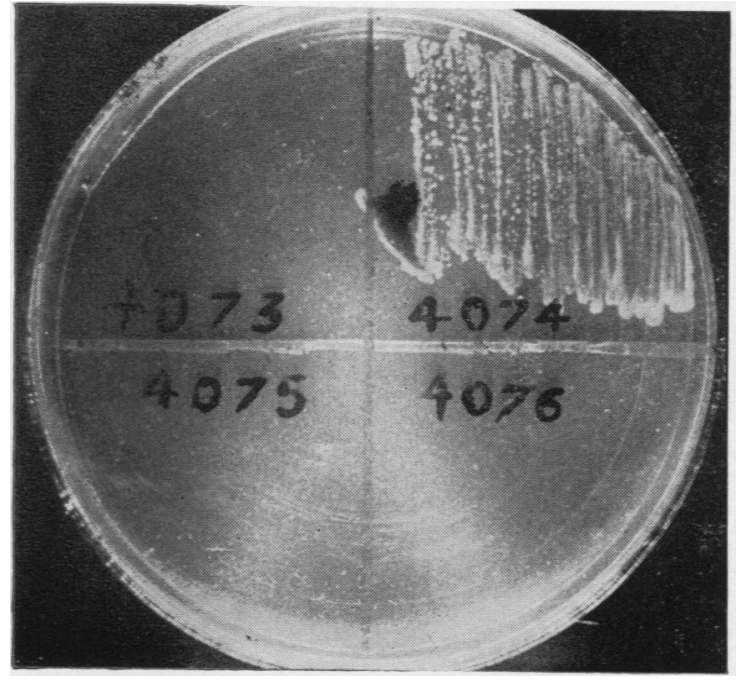

FIG. Lo.- - Smear from the new enrichment medium on an SS agar plate. The enrichment medium was inoculated with the same suspensions as in Fig. 2a.

The results presented in Table III demonstrafe the superiority of the new enrichment medium over selenite broth and tetrathionate broth. The new medium is, however, not suitable for the isolation of $S$. typhi; this organism is inhibited by malachite green at the concentration employed. When the concentration is lowered, contaminants may develop. We agree with Wundt (1954) that at present selenite broth is the most suitable enrichment medium for S. typhi.

\section{Summary}

A new enrichment medium for the cultivation and isolation of Salmonellae from faeces is described.

The ingredients in this medium, which inhibit the growth of coliform contaminants and permit unrestricted development of Salmonellae, are magnesium chloride (4\%), and malachite green $(0.012 \%)$. The medium was found to be superior for enrichment of Salmonellae, with the exception of $S$. typhi, to selenite enrichment broth and tetrathionate broth.

An important modification of the inoculation procedure is the use of a 1:1000 suspension of faeces for inoculation of the enrichment medium. This dilution ensures freedom from contamination by coliforms and does not decrease the number of isolations of Salmonellae.

The authors wish to express grateful thanks to Edward Gurr, Ltd., London, S.W.14 ; to J. R. Geigy, Ltd., Basle ; to Sandoz, Ltd., Basle ; and to Ciba, Ltd., for making available the dyes used in this study.

This work was done on a research grant from the Hebrew University Hadassah Research Fund. 


\section{REFERENCES}

Banwart, G. J., and Ayres, J. C. (1953). Appl. Microbiol., 1, 296. Biechteler, W. (1952). Zbl. Bakt., Orig., 158, 53.

Dold, H., and Ketterer, M. (1943). Z. Hyg. InfektKr., 125, 215.

Gillert K. E. (1954). Zbl. Bakt., Orig., 160, 463.

Hobbs, B. C., and Allison, V. D. (1945). Monthly Bull. Minist. Hlth (Lond.), 4, 63. Cited by Taylor. J., in Recent Advances in Clinical Pathology, ed. Dyke, S. C., 2nd ed., pp. 14-15.

Kauffmann, F. (1930). Zbl. Bakt. (Orig.), 119, 149.

Knox, R., Gell, P. G. H., and Pollock, M. R. (1942). J. Path. Bact., 54, 469.

Lang. K. (1952). Zbl. Bakt., Orig., 157, 565.

- (1954). Ibid., 161, 165.

Leifson, F. (1936). Amer. J. Hy'g. 24423.
Lie Kian Joe (1950). Docum, neerl, indones, morb. trop., 2, 113.

Lodenkämper, H. (1952). Zbl. Bakt., Orig., 158, 73.

Loeffler, F. (1906). Dtsch. med. Wschr., 32, 295.

- (1909). Ibid., 35, 1301.

Macierewicz, M., Strzelecka, M., and Zuleska, H. (1954). Med. dosw. mikrobiol., 6, 227.

Muller, L. (1923). C. R. Soc. Biol. (Paris), 89, 434.

Preuss, H. (1949). Z. Hyg. InfektKr., 129, 187.

Rappaport, F., and Henig, E. (1951). Amer. J. clin. Path. 21, 789.

Skariton-Loewenthal, M., and Olitzki, A. L. (1953). Bull. Re's. Coun. (Israel), 2, 448.

Schönberg, F.. and Wiidik, R. (1937). Berl. tierärztl. Wschr., p. 310 Wild, A. (1952). Vet. med. thesis, Giessen. Cited by Lang (1954).

Wundt, W. (1954). Zbl. Bakt., Orig., 160, 494. 